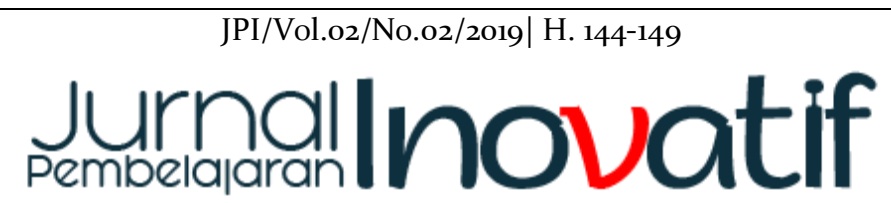

http://journal.unj.ac.id/unj/index.php/jpi

\title{
Rancangan Pembelajaran Flipped Classroom Untuk Mata Kuliah Persepsi Desain dan Pesan
}

\author{
Hana Alodianada, ${ }^{1 \circledast}$ Retno Widyaningrum $^{2}$, Kunto Imbar Nursetyo ${ }^{2}$ \\ ${ }^{1}$ Universitas Negeri Jakarta, Jakarta, Indonesia. \\ 2 Universitas Negeri Jakarta, Jakarta, Indonesia. \\ 3 Universitas Negeri Jakarta, Jakarta, Indonesia. \\ DOI: https://doi.org/10.21009/IPI.022.o8
}

\begin{tabular}{l}
\hline Article History \\
\hline Received : 2019 \\
Accepted : 2019 \\
Published : 2019 \\
\hline Keywords \\
\hline Keywords 1 flipped \\
classroom; 2 rapid \\
prototyping; 3 \\
rancangan \\
pembelajaran; 4 model \\
PEDATI; 5 blended \\
learning.
\end{tabular}

Article History

Received : 2019

Accepted : 2019

learning.

\begin{abstract}
Abstrak
Penelitian pengembangan ini bertujuan untuk menghasilkan produk berupa pembelajaran flipped classroom dalam bentuk RPKPS sebagai pedoman untuk melaksanakan pembelajaran flipped classroom pada mata kuliah PDP di Prodi Teknologi Pendidikan Universitas Negeri Jakarta. Penelitian pengembangan ini dilakukan dengan prosedur model pengembangan Rapid Prototyping, yakni 1) Assess Needs \& Analyze Content 2) Set Objectives, 3) Construct Prototype, 4) Utilize Product, 5) Installation \& Maintenance. Evaluasi pada penelitian pengembangan produk ini dilakukan melalui Expert Review. Tahap expert review melibatkan 1 orang ahli materi dan 2 orang ahli desain pembelajaran. Nilai rata-rata yang diperoleh dari ahli materi sebesar 3,48 yang berarti sangat baik. Nilai rata-rata yang diperoleh dari ahli desain pembelajaran 1 sebesar 3,21 yang berarti baik. Nilai rata-rata yang diperoleh dari ahli desain pembelajaran 2 sebesar 3,24 yang berarti baik. Dari hasil tersebut dapat disimpulkan bahwa rancangan pembelajaran flipped classroom untuk mata kuliah Persepsi Desain dan Pesan dinilai sudah baik.
\end{abstract}




\section{PENDAHULUAN}

Di abad ke 21 ini, pembelajaran berpusat pada peserta didik atau lebih dikenal dengan istilah learner oriented, artinya pembelajaran bertujuan agar peserta didik dapat mengalami proses pembelajaran dengan baik, sehingga tidak hanya hasil belajarnya saja yang baik. Perkembangan teknologi turut berdampak pada pembelajaran. Salah satunya adalah proses pembelajaran electronic learning atau biasa disingkat e-learning yang merupakan penerapan teknologi informasi dalam pembelajaran. Berbagai macam model online learning, sebagai bagian dari e-learning, dibuat untuk menyelenggarakan pembelajaran yang learner oriented.

E-learning juga akan membuat pembelajaran menjadi lebih ekonomis dengan tetap membuat peserta didik aktif karena dapat berdiskusi dengan pembelajar atau teman lainnya secara maya, juga akan menjadikan pembelajaran tidak terikat waktu karena dapat dilakukan kapan saja.

Mata kuliah Persepsi dan Desain Pesan merupakan mata kuliah yang berbobot 3 (tiga) sks yang diberikan pada semester 1. Adapun tujuan dari mata kuliah ini adalah agar mahasiswa dapat merancang suatu pesan dengan menerapkan prinsip-prinsip disain pesan untuk keperluan pembelajaran atau tujuan tertentu lainnya. Berdasarkan hasil wawancara dengan beberapa mahasiswa yang sudah mengambil mata kuliah tersebut, berpendapat bahwa mata kuliah Persepsi dan Desain Pesan memiliki tugas yang cukup banyak dan memakan waktu jika harus dikerjakan untuk setiap pertemuan tatap muka.

Oleh karena itu, tugas tersebut lebih sering dikerjakan di rumah untuk kemudian dikumpulkan pada pertemuan tatap muka berikutnya. Sementara itu, karena terbatasnya waktu yang tersedia selama tatap muka, dosen seringkali kesulitan untuk me-review tugas mahasiswa dari pertemuan sebelumnya sekaligus memberikan materi baru. Hal ini yang membuat tidak semua tugas-tugas mahasiswa sempat di-review oleh dosen dan mahasiswa lainnya selama pertemuan tatap muka. Padahal dengan me-review tugas-tugas tersebut, mahasiswa dapat lebih memahami materi yang sedang dipelajari.
Teknologi Pendidikan adalah studi dan praktek etis dalam memfasilitasi belajar dan meningkatkan kinerja dengan cara menciptakan, menggunakan, serta mengelola proses teknologi dan sumber-sumber yang tepat (AECT, 2004). Peran profesi Teknolog Pendidikan dalam masalah ini sangat besar karena termasuk dalam memfasilitasi dosen pengampu mata kuliah tersebut serta para mahasiswa yang mengambil mata kuliah tersebut. Permasalahan dalam penelitian ini dibatasi pada pengembangan flipped classroom pada mata kuliah Persepsi dan Desain Pesan di Program Studi Teknologi Pendidikan Universitas Negeri Jakarta. Fokus dari pengembangan ini adalah menghasilkan rancangan pembelajaran yang mengadaptasi model flipped classroom beserta bahan ajar yang siap digunakan merujuk pada rancangan pembelajaran yang mengadaptasi model flipped classroom untuk Mata Kuliah yang dibahas sebelumnya.

\section{METODE}

Dalam pengembangan ini, model pengembangan yang digunakan adalah model Rapid Prototyping yang memiliki lima tahap di dalamnya. Tahap pertama adalah Assess Needs \& Analyze Content, Set Objectives, Construct Prototype (Design), Utilize Prototype (Research), Install \& Maintain System. Kemudian dalam pengkajian prototype, terdaapat instrumen yang sudah divalidasi. Instumen yang digunakan berbentuk kuisioner yang bertujuan untuk mengukur kelayakan prototype yang dikembangkan. Instrumen ini menggunakan skala Likert dengan rentang bobot 1 sampai 4. Teknik analisis data yang dilakukan terhadap instrument evaluasi, berupa ceklis dengan skala penilaian 1 hingga 4 . Sampel yang dilibatkan adalah 15 orang responden mahasiswa Teknologi Pendidikan angkatan 2018 yang sudah mengikuti mata kuliah PDP sebelumnya. Sedangkan ahli yang dilibatkan adalah satu orang ahli materi dan dua orang ahli desain pembelajaran.

\section{HASIL DAN PEMBAHASAN}

Pengembagan ini dilakukan pada bulan juni 2019 hingga Juli 2019, yang jika ditotal maka waktu pengembangan ini berdurasi 
selama dua bulan. Responden yang dilibatkan dalam pengembangan ini ialah dosen pengampu mata kuliah Persepsi Desain dan Pesan, serta lima belas orang mahasiswa Teknologi Pendidikan angkatan 2018 yang sudah mengikuti mata kuliah PDP sebelumnya. Selanjutnya, akan dijelaskan mengenai proses pengembangan yang dilakukan, dokumentasi contoh proses pengembangan, hasil review para ahli; dari ahli materi dan ahli desain pembelajaran, hingga keterbatasan yang ada dalam pengembangan ini.

Pertama, pada tahap Asses Needs \& Analyze Content pengembang melakukan diskusi dengan Ibu Retno Widyaningrum sebagai dosen pengampu mata kuliah Persepsi dan Desain Pesan. Dari diskusi tersebut didapatkan beberapa fakta mengenai proses pembelajaran mata kuliah Persepsi dan Desain Pesan yang selanjutnya akan pengembang singkat menjadi PDP.

Fakta yang ditemukan ialah, pembelajaran PDP terdapat perubahan nama mata kuliah yang pada angkatan-angkatan sebelumnya merupakan mata kuliah Prinsip Desain Pesan. Namun kini menjadi mata kuliah Persepsi Desain dan Pesan, pembelajaran PDP yang pada angkatan-angkatan sebelumnya diberikan pada semester 3 (tiga), namun dipindahkan menjadi semester 1 (satu) dengan kata lain mahasiswa baru, dalam pembelajaran PDP yang pada angkatan-angkatan sebelumnya berjumlah 2 sks, namun kini menjadi 3 (tiga) sks, mengingat adanya beberapa tambahan materi, bahwa terdapat topik maupun konsep yang kurang diberikan secara maksimal karena keterbatasan waktu, terdapat pula tugas-tugas yang tidak dapat dibahas bersamaan dengan para mahasiswa yang juga disebabkan oleh waktu yang terbatas. Selain itu, diperoleh juga data-data dari sampel yang mana dapat disimpulkan bahwa sebagian besar mahasiswa menginginkan adanya pembelajaran online dalam mata kuliah PDP. Hal ini didukung karena mahasiswa sudah dapat memiliki perangkat keras untuk mengakses internet, serta sudah menguasai penggunaan internet itu sendiri.

Dari data yang didapatkan dari sampel dan atas persetujuan ahli materi pengembang memfokuskan pengembangan flipped classroom hanya untuk Pokok Bahasan 9 hingga Pokok Bahasan 16. Adapun pokok bahasan 9 hingga pokok bahasan 16, tidak terdapat perubahan karena sudah mencukupi capaian pembelajaran yang akan dicapai.

Kedua, dalam tahap Set Objectives pengembang berdiskusi dengan dosen pengampu mata kuliah Persepsi Desain dan Pesan (PDP) terkait capaian pembelajaran yang akan dirumuskan. Dari diskusi tersebut, menghasilkan sebuah keputusan bahwa capaian pembelajaran yang akan digunakan ialah capaian pembelajaran yang sudah ada sebelumnya. Hal ini dikarenakan tidak ada kata yang menghambat untuk dikembangkan menjadi berbasis flipped classroom. Sehingga, capaian pembelajaran yang menjadi tujuan pembelajaran dalam RPKPS sebelumya, dapat tetap digunakan.

Ketiga, dalam tahap Construct Prototype (Design) pengembang melakukan pengembangan prototype pembelajaran flipped classroom sebanyak tiga kali karena tahap ini berjalan seperti sebuah siklus dengan tahap selanjutnya. Meskipun begitu, pengembang memulai pengembangan dengan mengadaptasi format desain pembelajaran blended dari model PEDATI yang dikembangkan oleh Uwes Chaeruman dalam disertasinya yang berhudul PEDATI (Pembelajaran Daring di Perguruan Tinggi).

Dalam percobaan pengembangan prototype yang pertama, pengembang mengacu pada format desain pembelajaran model PEDATI. Pada proses tersebut pengembang melakukan merumuskan capaian pembelajaran, memetakan dan mengorganisasikan materi, menyusun setting pembelajaran, menyusun strategi pembelajara asinkronus, kemudia menyusun strategi pembelajaran sinkronus. Setelah berdiskusi dengan para ahli, dari proses percobaan pertama ini ditemukan kekurangan seperti warna tabel cenderung kusam/kurang cerah, masih kurang terlihat flipped classroomnya, terdapat pengulangan di beberapa kolom, sebaiknya bisa digabungkan agar menjadi lebih efisien, kolom asesmen pada tabel strategi pembelajaran sinkronus, dapat di isi butir soal yang akan dikerjakan pada saat tatap muka, pada saat asinkronus online, kolom sumber digital dapat dipecah menjadi kolom khusus bahan ajar literatur dan video. Dapat pula ditambahkan kolom visual dan juga kolom untuk mengisi link atau URL. Dengan 
mempelajari kekurangan tersebut, maka pengembangan berlanjut pada percobaan kedua.

Dalam pengembangan yang kedua ini, pengembang merevisi Rancangan Program Kegiatan Pembelajaran Semester (RPKPS) berbasis flipped classroom sesuai dengan apa yang didapatkan dari hasil diskusi sebelumnya. Adapun yang direvisi ialah seperti, merancang keseluruhan tabel yang ada di model PEDATI menjadi 1 tabel agar lebih efisien, mengganti warna tabel menjadi lebih menarik agar tidak kusam, membedakan warna pada garis tabel pada kolom asinkronus dan sinkronus, membedakan warna pada judul kolom asinkronus dan sinkronus, merubah tabel strategi pembelajaran asinkronus menjadi kolom dengan judul asinkronus online, dimana pada kolom tersebut terbagi menjadi empat, yaitu kolom bahan ajar literatur yang diberi judul Reading Text, kolom bahan ajar berupa visual yang diberi judul Visual, kolom bahan ajar berupa video yang diberi judul Video, kolom bahan ajar berupa website yang diberi judul URL, merubah tabel strategi pembelajaran sinkronus menjadi kolom dengan judul sinkronus TM (Tatap Muka), dimana pada kolom tersebut terbagi menjadi dua, yaitu kolom metode pembelajaran yang digunakan; yang diberi judul Metode, serta kolom media dan alat pembelajaran yang diberi judul Media \& Alat, menghilangkan tabel Setting Pembelajaran, karena seperti yang sudah dijelaskan sebelumnya bahwa dalam pembelajaran flipped classroom, kedua aktifitas asinkronus dan sinkronus akan selalu ada dalam setiap materinya. Selain itu, tujuan dari kolom ini secara tidak langsung sudah diwakilkan dengan adanya kolom Asinkronus Online dan Sinkronus TM. Adapun hasil revisi tersebut ditampilkan dalam Lampiran.

Setelah berdiskusi kembali dengan para ahli, ditemukan kekurangan seperti RPKPS masih dirasa 'buntung', dalam artian tidak ada pembuka atau kalimat-kalimat penghubung dari pembelajaran konvensional ke flipped classroom, sebelum memasuki strategi pembelajaran, identitas mata kuliah masih kurang, perlu adanya cover, tabel dirasa terlalu padat kesamping, sehingga masih perlu adanya efisiensi tabel, learning guide perlu dimasukkan ke dalam RPKPS, tepatnya di dalam kolom Asinkronus Online, perlu adanya skenario pembelajaran untuk aktifitas tatap muka, perlu adanya sumber belajar supaya dapat menjadi referensi, judul kolom Asinkronus Online dapat diubah menjadi bahasa Indonesia secara keseluruhan. Dari kesimpulan hasil diskusi tersebut, maka pengembang melakukan pengembangan yang ketiga untuk memperbaiki yang masih kurang atau perlu perbaikan.

Dalam pengembangan yang ketiga ini pengembang merevisi Rancangan Program Kegiatan Pembelajaran Semester (RPKPS) berbasis flipped classroom sesuai dengan apa yang didapatkan dari hasil diskusi yang sudah dilaksanakan dengan ahli yaitu Bapak Imbar dan Ibu Diana. Adapun hal yang dilakukan dalam tahap ini untuk merevisi RPKPS adalah seperti, merancang cover sebagai identitas RPKPS berbasis flipped classroom, menambahkan satu halaman dimuka yang berisikan identitas mata kuliah Persepsi Desain dan Pesan serta penjelasan singkat mengenai flipped classroom, merancang layout yang seragam dengan cover agar menjadi lebih layak, merubah tabel dengan memindahkan judul kolom menjadi judul baris. Dengan mengubah hal tersebut, maka tabel jadi lebih mengacu pada pokok bahasan. Sehingga masing-masing pokok bahasan akan memiliki satu tabel dengan format yang sama, mengubah nama judul kolom Asinkronus Online menjadi Asinkronus Maya, menambahkan Learning Guide yang ada di coursesite ke dalam judul baris Asinkronus Maya di dalam RPKPS berbasis flipped classroom, mengubah nama judul kolom Sinkronus TM menjadi Sinkronus Langsung (Tatap Muka, menambahkan skenario pembelajaran untuk digunakan pada saat aktifitas tatap muka, ke dalam RPKPS berbasis flipped classrom. Tepatnya didalalam judul baris Sinkronus Langsung (Tatap Muka, menambahkan daftar sumber belajar pada halaman paling belakang yang dapat digunakan sebagai refernsi tambahan dalam mencari bahan ajar. Adapun hasil revisi tersebut ditampilkan dalam Lampiran.

Setelah berdiskusi kembali dengan Ibu Diana dan Bapak Imbar, RPKPS berbasis flipped classroom sudah lebih layak digunakan. Sehingga, tahap construct prototype sudah dapat dihentikan dan prototype pembelajaran flipped classroom yakni berupa RPKPS berbasis flipped classroom dapat direview oleh para ahli yang sudah ditetapkan sebelumnya. 
Keempat, dalam tahap Utilize Prototype (Research) pengembang menyiapkan segala kebutuhan pembelajaran dari prototype yang sudah dikembangkan untuk coursesite, mulai dari learning object hingga learning guide. Materi perkuliahan berasal dari dosen pengampu PDP yang dimodifikasi menjadi lebih baik dan menarik. Berikut adalah dokumentasi dari persiapan learning object dan learning guide hingga proses mengunggah kedua hal tersebut ke dalam coursite Hylearn.

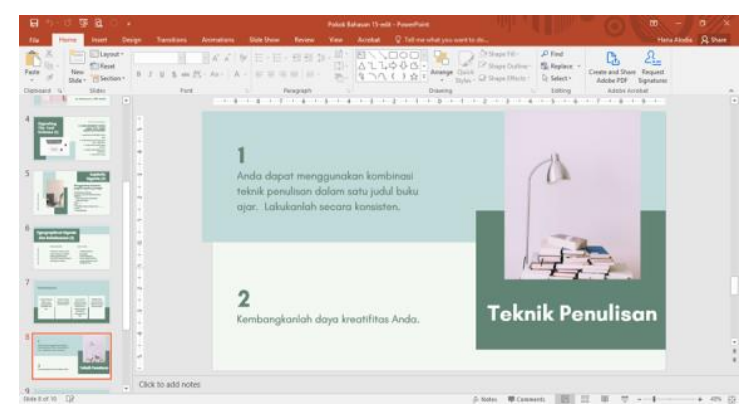

Gambar 1 Proses merancang learning object untuk Pokok Bahasan 15

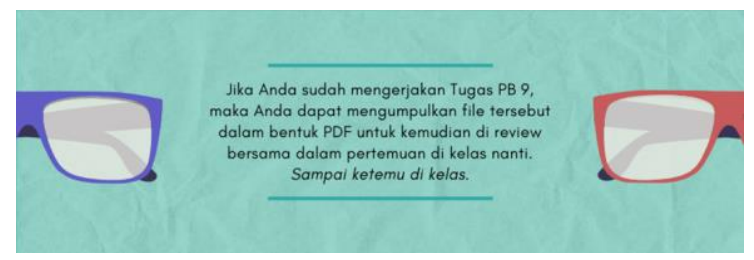

Gambar 2 Hasil desain learning guide untuk Pokok Bahasan 9

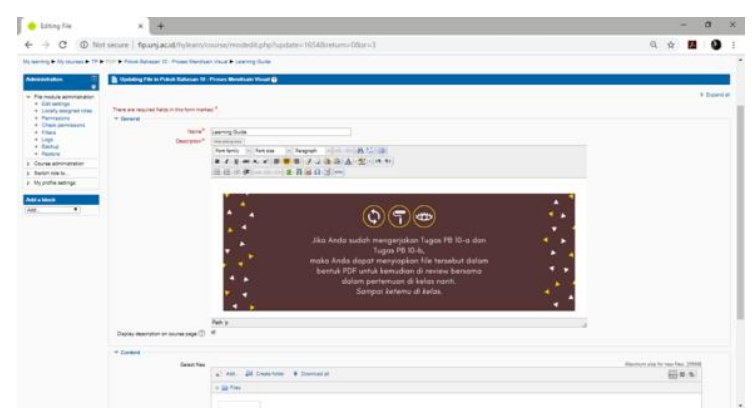

Gambar 3 Proses pengunggahan learning guide ke dalam coursesite

Setelah coursesite selesai disiapkan sesuai dengan RPKPS berbasis flipped classroom, maka tahap selanjutnya adalah mengumpulkan expert review.
Ahli materi yang dilbatkan dalam review produk ini adalah Ibu Retno Widyaningrum,S.Sos.,M.M sebagai dosen pengampu dari mata kuliah Persepsi Desain dan Pesan. Ibu Retno mengevaluasi materi yang terdapat di dalam coursesite / Hylearn untuk mata kuliah Persepsi Desain dan Pesan. Review dari Ibu Retno ialah materi dibuat jangan turun ke bawah, tampilan banner didesain supaya tidak terlalu berbeda-beda, beberapa perbaikan pada soal evaluasi. Adapun hasil skor dari penilaian Ibu Retno adalah sebagai berikut.

Tabel 1 Rata-rata penilaian dari ahli materi

\begin{tabular}{|c|l|c|}
\hline No. & Aspek & Rata-rata \\
\hline 1 & Pembelajaran & 3.75 \\
\hline 2 & Konten & 3.375 \\
\hline 3 & Penyajian & 3.14 \\
\hline 4 & Bahasa & 3.67 \\
\hline \multicolumn{2}{|c|}{ Total Rata rata } & 3.48 \\
\hline
\end{tabular}

Hasil akhir dari keseluruhan aspek mendapat nilai 3.48 yang berartikan bahwa dari sudut pandang ahli materi, produk ini sangat baik.

Tabel 2 Rata-rata penilaian dari ahli desain pembelajaran 1

\begin{tabular}{|c|l|c|}
\hline No. & Aspek & Rata-rata \\
\hline $\mathbf{1}$ & Desain Pembelajaran & 3.44 \\
\hline $\mathbf{2}$ & $\begin{array}{l}\text { Tampilan } \\
\text { Muka/Interface }\end{array}$ & 3.45 \\
\hline 3 & Learning Object & 3.1 \\
\hline 4 & Bahasa & 3 \\
\hline 5 & Flipped Classroom & 3.05 \\
\hline \multicolumn{2}{|c|}{ Total Rata rata } & 3.21 \\
\hline
\end{tabular}

Hasil akhir dari keseluruhan aspek mendapat nilai 3.21 yang berartikan bahwa dari sudut pandang ahli desain pembelajaran 1, produk ini baik.

Sementara itu ahli desain pembelajaran 2 yang dilbatkan dalam review produk ini 
adalah Bapak Cecep Kustandi,M.Pd. sebagai dosen di Program Studi Teknologi Pendidikan Universitas Negeri Jakarta yang juga familiar dengan pembelajaran flipped classroom. Bapak Cecep mengevaluasi RPKPS berbasis flipped classroom dan juga coursesite Hylearn untuk mata kuliah Persepsi Desain dan Pesan. Review dari Bapak Cecep ialah tambah tujuan pembelajaran, tambah interktivitas, tambah motivasi pada learning guide. Adapun hasil skor dari penilaian Bapak Cecep adalah sebagai berikut.

Tabel 3 Rata-rata penilaian dari ahli desain pembelajaran 2

\begin{tabular}{|c|l|c|}
\hline No. & Aspek & Rata-rata \\
\hline $\mathbf{1}$ & Desain Pembelajaran & 3.22 \\
\hline $\mathbf{2}$ & $\begin{array}{l}\text { Tampilan } \\
\text { Muka/Interface }\end{array}$ & 3.18 \\
\hline 3 & Learning Object & 3.1 \\
\hline 4 & Bahasa & 3 \\
\hline 5 & Flipped Classroom & 3.68 \\
\hline & Total Rata rata & 3.24 \\
\hline
\end{tabular}

Hasil akhir dari keseluruhan aspek mendapat nilai 3.24 yang berartikan bahwa dari sudut pandang ahli desain pembelajaran 2, produk ini baik.

Keempat, dalam tahap Install \& Maintain System, pengembang seharusnya meng $\neg$-install pembelajaran flipped classroom ke dalam kelas atau pembelajaran Persespsi Desain dan Pesan yang sesungguhnya. Namun karena adanya keterbatasan penelitian, tahap penerapan ini tidak dapat peneliti laksanakan. Sehingga pengembangan ini berakhir di tahap sebelumnya yaitu tahap Utilize Prototype.

\section{SIMPULAN}

Berdasarkan dari proses dan hasil pengembangan yang ada, diperoleh kesimpulan bahwa produk atau output yang dihasilkan dari pengembangan ini adalah berupa sebuah Rancangan Program Kegiatan Pembelajaran Semester (RPKPS) yang berbasis flipped classroom dengan coursesite Hylearn sebagai pendukung RPKPS berbasis flipped classroom tersebut.

\section{UCAPAN TERIMA KASIH}

Terima kasih pada Bapak dan Ibu Dosen di Program Studi Teknologi Pendidikan Universitas Negeri Jakartaserta para mahasiswa angkatan 2018 yang sudah terlibat dalam penulisan artikel ilmiah akademik ini.

\section{DAFTAR PUSTAKA}

Siregar, E. \& Nara, H., 2007. Teori Belajar dan Pembelajaran. Jakarta: Universitas Negeri Jakarta.

Pribadi, B. A., 2009. Model Disain Sistem Pembelajaran. Jakarta: Dian Rakyat.

Flipped Learning Network, 2014. The Four Pillars of F-L-I-P. What Is Flipped Learning?, pp. 1-2.

Miarso, Y., 2004. Menyemai Benih Teknologi Pendidikan. Jakarta: Prenada Meida.

Bates, J. E., Almekdash, H. \& Gilchrest-Dunnam, M. J., 2017. The Flipped Classroom: A Brief, Brief History. Texas: Springer International Publishing Switzerland. 